\title{
The Correlation between Periodontal Diseases and Chronological Age among Type 2 Diabetes Mellitus Patients attending at National Healthcare Network (NHN) Mirpur Centre, Dhaka, Bangladesh
}

\author{
MAHMUD SZ ${ }^{\mathrm{a}}$, ALIF SM ${ }^{\mathrm{b}}$, TARAFDER MA ${ }^{\mathrm{c}}$, HOSSAIN SM
}

\begin{abstract}
Background: The relationship between diabetes and periodontal diseases has been studied extensively during the past 50 years. Type 2 diabetes occurs mainly in people aged over 40, although it is affecting a growing number of young people. Patients with uncontrolled diabetes have poor resistance to infection with effects in mouth cavity and elsewhere in the body and show an unusually high susceptibility to periodontal diseases and increased susceptibility to acute lateral periodontal abscesses.
\end{abstract}

Objective: This descriptive type of cross-sectional study was conducted to find out the relationship between periodontal diseases and chronological age among type 2 diabetes mellitus patients attending at National Healthcare Network (NHN) Mirpur Centre, Dhaka.

Materials and Methods: A total 120 type 2 diabetic patients attended at diabetic centre for routine checkup over a period of six months from August 2011 to January 2012 who fulfilled the eligibility criteria were selected consecutively. Pre-tested semi structured interviewer administered questionnaires were

a. Dr. Shaikh Zakir Mahmud, BDS, MPH, Medical Officer (Dental Surgeon), National Healthcare Network (NHN) Mirpur Centre, Dhaka.

b. Dr. Sheikh Mohammad Alif, BDS, MPH, Assistant Professor, Department of Public Health, Northern University Bangladesh.

c. Dr. Monowar Ahmad Tarafder, MBBS, DIH, MPhil, PhD, Professor \& Head, Department of Community Medicine, Zalalabad Ragib Rabeya Medical College, Sylhet.

d. Dr. (Lt. Col) Sarder Mahmud Hossain, MBBS, DHM, PhD, Associate Professor, Department of Public Health, Northern University Bangladesh.

Address of correspondence: Dr. Shaikh Zakir Mahmud, BDS, MPH, Medical Officer (Dental), NHN Mirpur Centre, Commercial Plot No. 27-28, Block-Kha, Main Road-1, Section-6, Mirpur, Dhaka-1216, Bangladesh, Email: suman79_bd@yahoo.com

Received: 14 October, 2012

Accepted: 09 July, 2013 used to collect the information. Cross tabulations and associations were determined by using the chi-square test and simple linear regression from Statistical Package for the Social Sciences where applicable.

Results: Chronological age of the patients was significantly associated with the manifestation of periodontal diseases $(p=0.004)$. Moreover, age was useful as a predictor of periodontal diseases as the correlation coefficients showed statistically significant result $(p=0.008)$. In addition, for each year increase of age of the patients there was $0.20 \%$ increase of occurrence of periodontal diseases.

Conclusion: Periodontal diseases can adversely affect the metabolic control of diabetes. Conversely, treatment of periodontal disease and reduction of oral inflammation may have a positive effect on the diabetic condition, although evidence for this remains somewhat equivocal.

Key words: Chronological age, correlation, diabetes mellitus, periodontal diseases.

(Birdem Med J 2013; 3(2): 74-79)

Introduction

Diabetes mellitus and periodontal diseases are two common chronic diseases that have long been considered to be biologically linked. ${ }^{1}$ The term periodontal diseases usually refers only to plaque related inflammatory diseases of the dental supporting tissues. ${ }^{2}$ Several attempts have been made to classify periodontal diseases according to its etiology and clinical manifestations. ${ }^{3}$ According to the 1999 International Workshop for Classification of Periodontal Diseases and Conditions in Oak Brook (Illinois, USA) which was the first international workshop on classification of periodontal diseases, a decision was made on a new classification of the diseases based on a comprehensive review of literature. The following classification of periodontal diseases was proposed: gingival diseases 
$(\mathrm{G})$, chronic periodontitis $(\mathrm{CP})$, aggressive periodontitis (AP), periodontitis as a manifestation of systemic diseases (PS), necrotizing periodontal diseases (NP), periodontal abscesses (PA), periodontitis with endodontic lesion, developed and acquired deformations and conditions. ${ }^{4}$

The American Diabetes Association (ADA) acknowledges the link between periodontal diseases and diabetes that periodontitis is often found in people with diabetes. ${ }^{5}$ In 2000, the American Academy of Periodontology (AAP) took a strong public stand on this issue in their 1999 position paper that acknowledges a bi-directional relationship between periodontal diseases and diabetes. ${ }^{6}$ The AAP statement recommends that the oral health professional contact clients' physicians to inform them of any periodontal diseases, since periodontal infection may increase insulin resistance, lead to a worsening of the diabetic state, and increase the risk for diabetic complications. ${ }^{7}$

The relationship between oral diseases and type- 2 diabetes has become a recent focus of attention among healthcare professionals because of substantial evidence supporting the role of diabetes and poor glycemic control as important risk factors for periodontal diseases. ${ }^{8}$ The research team analyzed randomized controlled trials of people with Type 1 and Type 2 diabetes who had also been diagnosed with periodontal diseases. Their findings suggested that the treatment of periodontal diseases could reduce blood sugar levels in Type 2 diabetes, although there was not enough available evidence to support the same benefit for those with Type 1 diabetes. ${ }^{9}$ The World Health Organization stated that oral diseases, including periodontal diseases, were a serious health problem and that increasing the awareness of oral health worldwide should be considered as an important component of general health and quality of life. ${ }^{10}$

\section{Materials \& Methods}

This descriptive type of cross-sectional study was conducted to assess the correlation between periodontal diseases and chronological age among type 2 diabetes mellitus patients attending at National Healthcare Network (NHN), Mirpur Centre which is an enterprise of Diabetic Association of Bangladesh. The study was carried out among 120 subjects - 47 male and 73 female, who were suffering from different periodontal diseases. To get the target sample quickly, nonrandomized purposive sampling technique was followed by using a pre-tested semi-structured questionnaires and a check-list. Patients with type 2 diabetes mellitus having glycosylated hemoglobin (HbAlc) level equal to or more than $7.0 \%$ were included in this study. On the other hand, patients who had not done $\mathrm{HbAlc}$ or had its level less than $7.0 \%$ were excluded from the study.

The severity of periodontitis was assessed clinically by measuring the depth of periodontal pocket using periodontal probe graduated in millimeters that was passed through the pocket up to the bottom. Probe was placed parallel to the long axis of individual tooth at six sites and the depth of the periodontal pocket was taken. Pressure during probing was exerted within the range of 20-25 gm. Periodontal index was followed according to Ramfjord (1967) whilst assessment of gingivitis was done according to Loe and Silness index (1967). Data were checked, cleaned and edited properly before analysis. The data were analyzed by using the software SPSS version 11.5. Descriptive statistics were used for interpretation of the findings. Associations were assessed by using the chi-square test $\left(\chi^{2}\right)$ and simple linear regression.

\section{Results}

The distribution of the patients according to the proportions of periodontal diseases is shown in Table 1. Proportion of periodontitis was the highest $55.8 \%$ followed by gingivitis $32.5 \%$, periodontitis with endodontic lesion exactly $5 \%$ and necrotizing periodontal diseases $4.2 \%$ whereas periodontal abscesses showing the lowest was $2.5 \%$.

Table-I

Distribution of the patients by the proportions of periodontal diseases $(n=120)$

Name of periodontal diseases Frequency Percentage

\begin{tabular}{lcc} 
& & (\%) \\
\hline Gingivitis & 39 & 32.5 \\
Periodontitis & 67 & 55.8 \\
Necrotizing periodontal diseases & 5 & 4.2 \\
Periodontal abscesses & 3 & 2.5 \\
Periodontitis with endodontic lesion & 6 & 5.0 \\
\hline Total & 120 & 100.0 \\
\hline
\end{tabular}


The distribution of the patients' chronological age in relation to periodontal diseases is provided in Table-II Maximum $34.2 \%$ (41) were in the age group of 36 to 45 years followed by $28.3 \%$ (34) in the age group of 46 to 55 years. Similarly $16.7 \%$ (20) were in the age group of 56 to $65,13.3 \%$ (16) were age group of with in 35 years and $7.5 \%$ (9) showing the minimum were in the age group of more than 65 years.

Simple linear regression analyzed between chronological age of the patients and periodontal diseases are given in Tables IV-VI. Model summary (Table-IV) shows that the correlation coefficient " $R$ " and the coefficient determination " $\mathrm{R}$ square" between the chronological age of the patients and manifestation of periodontal diseases. For "R square" we should take the value of $R$ square from the table, which was 0.059 . " $\mathrm{R}^{2}=0.05$ " indicates that about $5 \%$ variation in periodontal diseases can be explained by chronological age of the patients. Rest of the $95 \%$ variation was due to other factors. "Adjusted R square" as shown in the table was the value (0.051), when "R square" was adjusted for better population estimate.
Table-II

Distribution of the respondents by chronological age $(n=120)$

Chronological age Frequency Percentage

(years) $\quad(\%)$

$35 \quad 16 \quad 13.3$

$\begin{array}{lll}36-45 & 41 & 34.2\end{array}$

$\begin{array}{lll}46-55 & 34 & 28.3\end{array}$

$\begin{array}{lll}56-65 & 20 & 16.7\end{array}$

\begin{tabular}{lcc}
$>65$ & 9 & 7.5 \\
\hline Total & 120 & 100.0
\end{tabular}

Median age $=46$ years $\quad$ Mean $\pm \mathrm{SD}=46.95 \pm 10.31$

Minimum age $=35$ years $\quad$ Maximum age $=75$ years

Statistically significant association between Chronological age of the patients and periodontal diseases is shown in Table-III where $p$ value was 0.004 .

Table-III

Association between chronological age of the patients and periodontal diseases $(n=120)$

\begin{tabular}{lcccccccc} 
Periodontal diseases & \multicolumn{4}{c}{ Chronological age (years) } & Total & p- \\
\cline { 2 - 6 } & 35 & $36-45$ & $46-55$ & $56-65$ & $>65$ & & value $^{\text {a }}$ \\
\hline Gingivitis & 10 & 19 & 7 & 2 & 1 & 39 & $0.004^{*}$ \\
Periodontitis & 4 & 18 & 23 & 16 & 6 & 67 & \\
Necrotizing periodontal diseases & 0 & 3 & 1 & 0 & 1 & 5 & \\
Periodontal abscesses & 2 & 0 & 0 & 1 & 0 & 3 & \\
Periodontitis with endodontic lesion & 0 & 1 & 3 & 1 & 1 & 6 & \\
\hline Total & 16 & 41 & 34 & 20 & 9 & 120 & \\
\hline
\end{tabular}

${ }^{a}$ Pearson Chi-Square Test* Statistically significant association $(\mathrm{p}<0.05)$

Table-IV

\begin{tabular}{|c|c|c|c|c|c|c|c|c|c|}
\hline \multicolumn{10}{|c|}{ Model Summary } \\
\hline \multicolumn{10}{|c|}{ Change Statistics } \\
\hline Mode & $\mathrm{R}$ & $\begin{array}{c}\mathrm{R} \\
\text { Square }\end{array}$ & $\begin{array}{l}\text { Adjusted } \\
\text { R Square }\end{array}$ & $\begin{array}{l}\text { Std. Error of } \\
\text { the Estimate }\end{array}$ & $\begin{array}{l}\text { R Square } \\
\text { Change }\end{array}$ & $\begin{array}{c}\mathrm{F} \\
\text { Change }\end{array}$ & DF1 & $\mathrm{DF} 2$ & $\begin{array}{r}\text { Sig. F } \\
\text { Change } \\
\end{array}$ \\
\hline 1 & $0.242^{\mathrm{a}}$ & 0.059 & 0.051 & 0.93319 & 0.059 & 7.358 & 1 & 118 & 0.008 \\
\hline
\end{tabular}

a Predictors: (Constant), Chronological age of the patientsDF- Degree of Freedom; R-Correlation Coefficient; $\mathrm{R}^{2}$ - Coefficient Determination

ANOVA (Table V) shows us whether the correlation coefficient " $R$ " was significant or not. As the p-value (Sig.) was 0.008 , "R" was significant. We can therefore, say at the $\alpha=0.05$ level of significance, there exists enough evidence to conclude that the slope of regression line was not zero and, hence, there was a positive correlation between periodontal diseases and chronological age of the patients and therefore can use the regression equation for prediction. 
Table-V

\begin{tabular}{ccccccc}
\multicolumn{7}{c}{ ANOVA $^{b}$} \\
Model & & Sum of Squares & Degree of Freedom & Mean Square & F & Sig. \\
\hline 1 & Regression & 6.407 & 1 & 6.407 & 7.358 & $0.008^{\mathrm{a}}$ \\
& Residual & 102.759 & 118 & 0.871 & & \\
& Total & 109.167 & 119 & & & \\
\hline
\end{tabular}

a Predictors: (Constant), Chronological age of the patients ${ }^{\mathrm{b}}$ Dependent Variable: Periodontal diseases; ANOVAAnalysis of Variance

Table-VI

\begin{tabular}{|c|c|c|c|c|c|c|c|c|}
\hline \multicolumn{9}{|c|}{ Coefficients ${ }^{a}$} \\
\hline \multirow[t]{2}{*}{ Model } & & \multicolumn{2}{|c|}{$\begin{array}{l}\text { Unstandardized } \\
\text { Coefficients }\end{array}$} & \multirow{2}{*}{$\begin{array}{c}\text { Standardized } \\
\text { Coefficients } \\
\text { Beta }\end{array}$} & \multirow[t]{2}{*}{$\mathrm{t}$} & \multirow[t]{2}{*}{ Sig. } & \multicolumn{2}{|c|}{$\begin{array}{l}95 \% \text { Confidence } \\
\text { Interval for B }\end{array}$} \\
\hline & & $\mathrm{B}$ & Std. Error & & & & Lower Bound & Upper Bound \\
\hline \multirow[t]{2}{*}{1} & (Constant) & 1.358 & 0.223 & & 6.098 & 0.000 & 0.917 & 1.799 \\
\hline & Age & 0.206 & 0.076 & 0.242 & 2.712 & 0.008 & 0.056 & 0.357 \\
\hline
\end{tabular}

a Dependent Variable: Periodontal diseases

Coefficients (Table-VI) give us the values of "a" or " $\beta_{0}$ " or Y-intercept (also called constant) and "b" or " $\beta_{1}$ " or slope (also called beta coefficient or regression coefficient). The slope indicates the amount of variation in Y (here it was periodontal diseases) due to each unit changed in $X$ (here it was chronological age of the patients). The table also shows the significance of "b" or " $\beta_{1}$ " which was 0.008 . The value for " $a$ " or " $\beta_{0}$ " and "b" or " $\beta_{1}$ " as indicated in the table were 1.358 and 0.206 respectively. The prediction equation for this simple linear regression was $\mathrm{Y}($ Dependent Variable $)=$ $1.358+0.206 \times$ (Independent Variable). So, for each year increase of chronological age of the patients there was $0.20 \%$ increase of occurrence of periodontal diseases.

\section{Discussion}

This cross-sectional study was conducted to assess the proportions of periodontal diseases in relation to chronological age among type 2 diabetes mellitus patients. Out of 120 patients, $60.8 \%$ were female while male were $39.2 \%$. To minimize bias due to misclassification of diabetes type, this study included only those subjects 35 years of age and older because it is recognized that over $95 \%$ of individuals with diabetes who are 35 years of age and older have type 2 Diabetes Mellitus.
In 2000, the American Academy of Periodontology (AAP) took a strong public stand on this issue in their 1999 position paper that acknowledged a bi-directional relationship between periodontal diseases and diabetes. ${ }^{9}$ Periodontal diseases are classified according to the severity of the disease. In fact, gingivitis and periodontitis are sometimes the first evidence that a patient has diabetes. ${ }^{11}$ According to WHO technical reports gingivitis is one of the most wide spread diseases in Bangladesh. ${ }^{12}$ Gingivitis was seen in approximately $75 \%$ of U.S. adults, about $13 \%$ have severe periodontitis, and $35 \%$ of those over age 30 have some form of periodontitis. ${ }^{13}$ In contrast, present study showed that proportions of periodontitis was $56 \%$ followed by gingivitis 33\%, periodontitis with endodontic lesion 5\% and necrotizing periodontal diseases $4.2 \%$ as well as periodontal abscesses showing the lowest $2.5 \%$ respectively (Table-I).

In 2002, one of the population-based survey in the US adult population showed that 7.8 million people diagnosed with diabetes, $90-95 \%$ have type 2 diabetes, while $5-10 \%$ have type 1 diabetes. Among individuals over 45 years old with diabetes, more than $95 \%$ have type-2 diabetes. ${ }^{14}$ Similar study done in 2010 showed type 2 diabetes occurred mainly in people aged over 40 , 
although it was affecting a growing number of young people. ${ }^{15}$ Current study also depicted that the mean age of the patients was $47 \pm 10.31$ (Mean \pm SD). In addition, $34.2 \%$ of the patients were belonging to the age group of 36 to 45 years followed by $28.3 \%$ were age group of 46 to 55 years (Table II). Another survey conducted on Report on the Findings of the Oral Health Component of the Canadian Health Measures Survey in the year 2007-2009 found that severe periodontal disease (pocket e" $6 \mathrm{~mm}$ ) was significantly higher amongst the oldest age group (14.8\%), those with lower incomes $(9.0 \%)$, and those born outside Canada $(12.4 \%) .{ }^{16}$ Almost similar result was found in the present study that supported the association between chronological age of the patients and periodontal diseases where p-value was 0.004 (Table III). What's more, chronological age was useful as a predictor of periodontal diseases as the p-value was 0.008 (Table IV$\mathrm{V})$. In fact, for each year increase of chronological age of the patients, there was $0.20 \%$ increase of the occurrence of periodontal diseases (Table-VI).

In 1990, a tentative model for decision making regarding periodontal care in relation to age has been depicted in a simplified form. By assuming that the alveolar bone level at 25 years is 'normal', one can draw a line which is the critical limit of the level of alveolar bone between age 25 and 75 years. As long as the alveolar bone is coronal of the critical limit, the tooth (person) might be considered safe. A soon as the resorption of the alveolar bone goes so fast that the level comes apical of the critical limit, the tooth (person) might be considered at risk and intervention should be considered. Periodontal treatment need would then be considered as the amount of treatment necessary to obtain or maintain the oral health goal. ${ }^{17}$

\section{Limitations}

This study would have needed a much larger sample size in order to generalize the results in Bangladeshi population. As there was limited time frame and resources to conduct the study, we used the most convenient formula to calculate the sample size. Therefore, the sample size became smaller which may decrease the statistical power.

Other limitation of this study was the veracity of the data collection by purposive sampling method using a semi-structured questionnaire. In this investigation, the homogeneity of the sample could not be ensured. For instance, respondents from the sex groups were not equal in number. Again, socioeconomic backgrounds of the patients were varied, as the family income depends upon the number of persons employed.

Oral health behavior mentioned in the questionnaire may differ from actual behavior, as the respondents have full authority to answer the questions as they liked and there was no system for cross check.

\section{Conclusion}

Periodontal diseases can adversely affect the metabolic control of diabetes. Conversely, treatment of periodontal disease and reduction of oral inflammation may have a positive effect on the diabetic condition, although evidence for this remains somewhat equivocal. Education and knowledge of diabetic patients are very important to prevent periodontal and oral diseases. Prevention campaigns should be concentrated on the younger age groups because the prevention component of lifestyle should be included and accepted at young age and as one cannot detect the real risk patient at young age (attachment loss for age), one might as well consider them all for the time being as belonging to the potential risk group.

\section{References:}

1. Taylor GW, Borgnakke WS. Periodontal disease: associations with diabetes, glycemic control and complications. Oral Diseases 2008;14(3):191-203.

2. Cawson RA, Odell EW. Gingivitis and Periodontitis. In: Premdas N, Urquhart J, editors. Essential of Oral Pathology and Oral Medicine, $6^{\text {th }}$ ed. London: Harcourt Publishers Ltd; 2000. p.63-85.

3. Mealey BL. Diabetes and periodontal disease: two sides of a coin. Compend Contin Educ Dent 2000;21(11):94350 .

4. PlanEak D, JorgiE-Srdjak K, CuriloviE Z. New Classification of Periodontal Diseases. Acta Stomat Croat 2001;35(1):89-93.

5. American Diabetes Association. Expert Committee on the Diagnosis and Classification of Diabetes Mellitus. Diabetes Care 2003 ;26(1): S5-S20.

6. Committee on Research, Science and Therapy. American Academy of Periodontology. Diabetes and periodontal diseases. J Periodontol 2000; 71(4): 664-78.

7. Lux J, Lavigne S. Your mouth-portal to your body: CDHA position paper on the links between oral health and general health. Part I. Probe 2004; 38(3):115-34. 
8. Smith RM, Fleming LE, Arheart KL, Wilkinson JD. Periodontal Disease and Diabetes: Knowledge and Attitudes Assessment Project. Florida Public Health Review 2007 ;4: 12-17.

9. Periodontal disease-Type 2 diabetes link confirmed. British Dental Journal [Online] $2010 ; 208$ : 447. Available from:http://www.nature.com/bdj/journal/v208/n10/full/ sj.bdj.2010.495.html [accessed 30 August 2011].

10. World Health Organization. Global policy for improvement of oral health in the 21 st centuryimplications to oral health research of World Health Assembly, 2007. Available from: http://www.who.int/ oral_health/publications/en/. [accessed 4 September $2011]$.

11. Ojehanon PI, Akhionbare O. Prevalence of undiagnosed diabetes mellitus among dental patients in Edo State, Nigeria. JMBR 2006; 5(1): 24-28.

12. Epidemiology, etiology and prevention of periodontal diseases. World Health Organization. Technical report series: 621 Geneva WHO, 1978. Journal of Public Health Dentistry $1979 ; 39(2): 163-67$.
13. Moritz A, Mealey B. Periodontal disease, insulin resistance, and diabetes mellitus: a review and clinical implications. Grand Rounds Oral-Sys Med 2006; 2: 13 20 .

14. Tsai C, Hayes C, Taylor GW. Glycemic control of type 2 diabetes and severe periodontal disease in the US adult population. Community Dent Oral Epidemiology 2002; 30: $182-92$.

15. Treatment of Gum Disease May Lower Blood Sugar Levels in Type 2 Diabetes. [News] The Peninsula College of Medicine and Dentistry; 2010. Available from: http:// www.diabetes 1.org/news/mainstory.cfm/120 [accessed 20 September 2011]

16. Report on the Findings of the Oral Health Component of the Canadian Health Measures Survey; 2007-2009.p.3739. Available from: http://www.fptdwg.ca/assets/PDF/ CHMS/CHMS-E-summ.pdf [accessed 9 October 2011].

17. Pine CM. Public health aspects of oral diseases and disorders: Periodontal diseases. In: Heinemann B, editor. Community Oral Health, $1^{\text {st }}$ ed. London: Reed Educational \& Professional Publishing Ltd; 1997. p. 82-87. 
treatment. ${ }^{11}$ Neonatal dermatologic disorders like infections can lead to life threatening sepsis if not taken seriously. The number of infantile dermatological disorders is quite big but the distribution pattern in Bangladesh is not well described in literature.

\section{Materials and Methods}

During the period of January 2010 to June 2012, a total of 36,608 children with skin diseases were treated. Among them 9293 children (25.38\%) were less than 1 year of age group and were included in this study. Diagnosis was made in most of the cases on clinical grounds by a dermatologist and in some cases laboratory investigations were done. Data were collected from the medical records kept during patient consultation. Data analysis were done using SPSS windows version 16 . For analysis disease pattern according to their frequency of distribution, sex, seasonal variation was done.

\section{Results}

During this study period of two and a half years a total of 9293 under one year children were seen of which neonates were 7\% $(n=649)$ and 93\% were infants $(n=8644)$. There were more male than female patients (5405 versus 3888). The ratio of male to female was 1.39:1 (Table-I). There were over 25 dermatoses which were treated in the OPD $(n=9293)$. Percentage of distribution was calculated from this number. As some patients had multiple diseases, total percentages will be higher than $100 \%$ (Table II).

Table-I

\begin{tabular}{|c|c|c|c|c|c|c|c|c|}
\hline \multicolumn{9}{|c|}{ Age distribution of patients under 1 year of age } \\
\hline \multicolumn{2}{|c|}{ Age Group } & Male (n) & Female (n) & Total Number of cases & \multicolumn{2}{|c|}{ Percentage $(\%)$} & \multicolumn{2}{|c|}{ Ratio (male: female) } \\
\hline \multicolumn{2}{|c|}{ Neonate (Up to 28 days) } & 400 & 249 & 649 & \multicolumn{2}{|c|}{7.0} & \multicolumn{2}{|c|}{$1.61: 1$} \\
\hline \multicolumn{2}{|c|}{ Infant (29 day-1 yr) } & 5005 & 3639 & 8644 & \multicolumn{2}{|c|}{93.0} & \multicolumn{2}{|c|}{$1.38: 1$} \\
\hline \multicolumn{2}{|l|}{ Total } & 5405 & 3888 & 9293 & \multicolumn{2}{|c|}{100} & \multicolumn{2}{|c|}{$1.39: 1$} \\
\hline \multicolumn{9}{|c|}{ Table-II } \\
\hline \multicolumn{9}{|c|}{$\begin{array}{l}\text { Distribution of skin disease pattern }(n=9293) \text { in infants. Percentage calculated from this number; however, } \\
\text { as some patient who had multiple diseases were also considered in the calculation. }\end{array}$} \\
\hline S1. no & \multicolumn{4}{|c|}{ Names of disease (in descending order of frequency) } & Male & Female & Number & $\%$ \\
\hline 1 & \multicolumn{4}{|c|}{ Eczema (including eczematization of other skin diseases) } & 3078 & 2071 & 5149 & 55.41 \\
\hline 2 & \multicolumn{4}{|c|}{ Bacterial Infections (Impetigo, Summer Boil, Cellulites, Pyoderma) } & 1468 & 1093 & 2561 & 27.56 \\
\hline 3 & \multicolumn{4}{|c|}{ Scabies } & 1281 & 897 & 2178 & 23.44 \\
\hline 4 & \multicolumn{4}{|c|}{ Tineasis, Candidiasis, Oral thrush } & 725 & 575 & 1300 & 13.99 \\
\hline 5 & \multicolumn{4}{|c|}{ Miliaria } & 245 & 210 & 455 & 4.90 \\
\hline 6 & \multicolumn{4}{|c|}{ Erythema Neonatorum } & 253 & 158 & 411 & 4.42 \\
\hline 7 & \multicolumn{4}{|c|}{ Urticaria } & 125 & 78 & 203 & 2.18 \\
\hline 8 & \multicolumn{4}{|l|}{ Bullous lesion } & 83 & 52 & 135 & 1.45 \\
\hline 9 & \multicolumn{4}{|l|}{ Haemangioma } & 46 & 63 & 109 & 1.17 \\
\hline 10 & \multicolumn{4}{|l|}{ Pityriasis Alba } & 51 & 56 & 107 & 1.15 \\
\hline 11 & \multicolumn{4}{|c|}{ Vulvo vaginitis } & 0 & 77 & 77 & 0.83 \\
\hline 12 & \multicolumn{4}{|c|}{ Pruritus ( vulvae, ani with or without excoriation \& others pruritus) } & 5 & 58 & 63 & 0.68 \\
\hline 13 & PEM with skin c & hange & & & 20 & 19 & 39 & 0.42 \\
\hline 14 & $\begin{array}{l}\text { Viral Infections } \\
\text { Chicken pox \& }\end{array}$ & $\begin{array}{l}\text { Wart inclu } \\
\text { ther viral } r\end{array}$ & $\begin{array}{l}\text { ling mollusc } \\
\text { sh) }\end{array}$ & um contagiosum, & 21 & 9 & 30 & 0.32 \\
\hline 15 & Phrynoderma & & & & 18 & 9 & 27 & 0.29 \\
\hline 16 & Drug reaction in & cluding St & ven Johnson' & 's syndrome \& FDE & 12 & 13 & 25 & 0.27 \\
\hline 17 & Epidermolysis B & ullosa & & & 10 & 8 & 18 & 0.19 \\
\hline 18 & Vitiligo \& Leuco & derma & & & 10 & 5 & 15 & 0.16 \\
\hline 19 & Hyperpigmentat & ion & & & 3 & 7 & 10 & 0.11 \\
\hline 20 & Paronychia & & & & 8 & 1 & 9 & 0.10 \\
\hline 21 & Alopecia & & & & 6 & 3 & 9 & 0.10 \\
\hline 22 & Lichen striatus & & & & 3 & 3 & 6 & 0.06 \\
\hline 23 & Angular stomati & is \& Oral L & lcer & & 1 & 2 & 3 & 0.03 \\
\hline 24 & ITP & & & & 0 & 1 & 1 & 0.01 \\
\hline 25 & TEN, SSSS, Acr & dermatitis & & & & & 4 & 0.04 \\
\hline
\end{tabular}


Eczema was found in $55.41 \%$ and was highest among all dermatoses. Any form of eczema when became chronic was grouped as a separate entity. Seborrheic variety topped the list ( $\mathrm{n}=3007,58.4 \%)$ in frequency followed by eczematization of other dermatosis $(\mathrm{n}=548,10.64 \%)$, contact $(n=730,14.18 \%)$ and atopic $(n=722,14.02 \%)$. Other forms of eczema like numular, primary irritant contact dermatitis (PICD), pompholyx and chronic eczema were low in frequency - each less than $1 \%$ (Fig.-1).

Bacterial infections in the form of impetigo, summer boil and pyoderma were next in frequency and they constituted $27.56 \%$ of the diseases. Of them impetigo was highest $(96.17 \%)$, followed by summer boil (1.91 $\% \%$ ), cellulitis (1.02\%) and pyoderma (0.9\%) (Fig.-2).

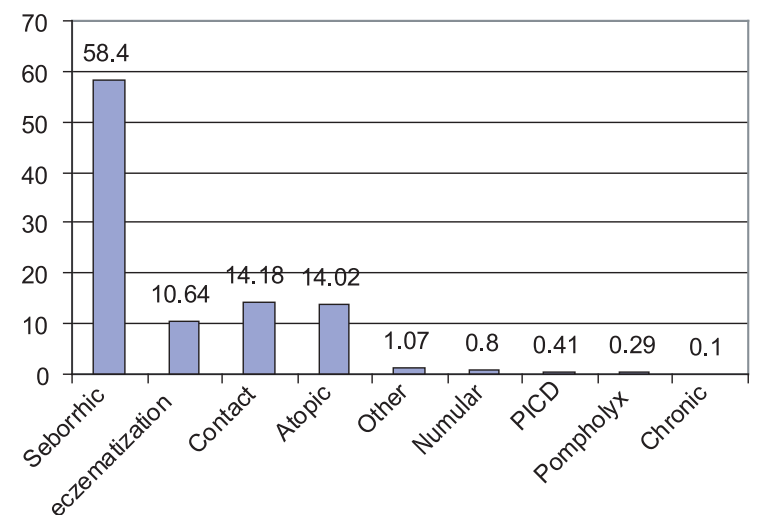

Fig.-1: Types of Eczema $(n=5149,55.41 \%$ of total patients) Eczematization of other dermatologic disorders were also included). Percentages within group are shown

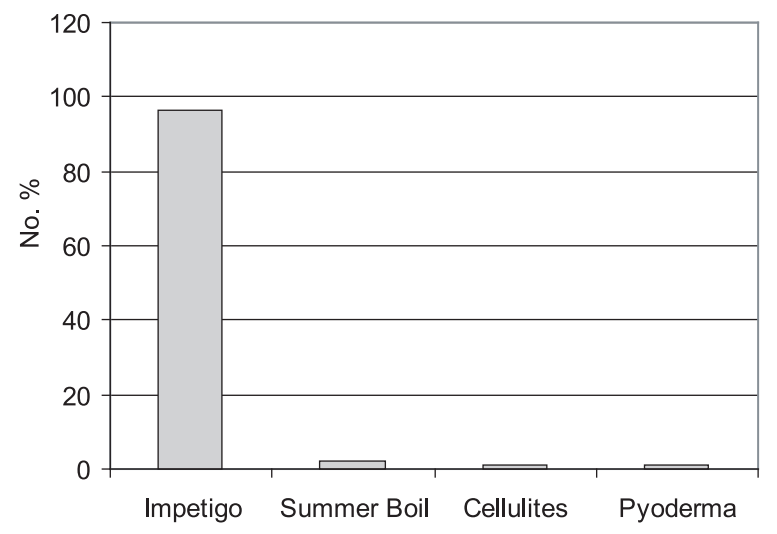

Fig.-2: Types of Bacterial infections $(n=2561.27 .56 \%$ of total patients). Four major variants shown in the figure.
Scabies constituted about a quarter $(23.44 \%)$ of the infantile dermatological conditions and most of the scabies $(72 \%)$ patients were secondarily infected (Table IV).

\section{Table-III}

Seborrheic Dermatitis (SD) in different age groups in children below 1 yr age $(n=9293)$

\begin{tabular}{lcccc} 
& $\begin{array}{c}\text { Total } \\
\text { number } \\
\text { of patient }\end{array}$ & $\begin{array}{c}\text { Number } \\
\text { with } \\
\text { SD }\end{array}$ & $\begin{array}{c}\text { \% of pts } \\
\text { within } \\
\text { group }\end{array}$ & $\begin{array}{c}\text { male: } \\
\text { female }\end{array}$ \\
\hline Neonates & 649 & 96 & 14.8 & 1.59 \\
29 days to 3 month & 1534 & 747 & 48.7 & 1.52 \\
3 to 6 month & 2207 & 956 & 43.3 & 1.43 \\
6 month to 1 yr & 4903 & 1208 & 24.6 & 1.48 \\
\hline Total & 9293 & 3007 & & 1.48 \\
\hline
\end{tabular}

Cutaneous fungal infections in the form of tineasis, candidiasis, pityriasis versicolor and oral thrush were $13.99 \%$ in frequency. Next in frequency were miliaria $(4.9 \%)$ and erythema neonatorum $(4.42 \%)$. Urticaria were $2.18 \%$, bullous lesions were $1.45 \%$, hemangiomas were $1.17 \%$.

Six major skin diseases in neonates (Fig.3) were erythema neonatorum $63 \%(\mathrm{n}=403)$, seborrheic dermatitis $14.79 \%$ $(\mathrm{n}=96)$, candidiasis $10.17 \%(\mathrm{n}=66)$, impetigo $8.94 \%$ $(\mathrm{n}=58)$, perianal excoriation $2.77 \%(\mathrm{n}=18)$ and miliaria $2.31 \%(\mathrm{n}=15)$.

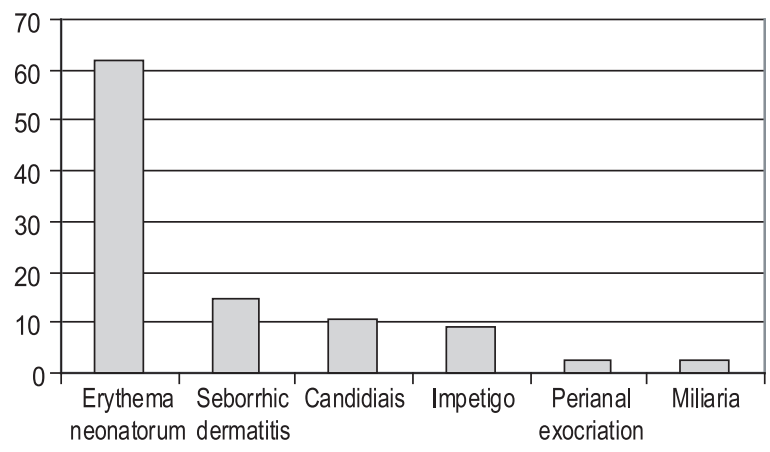

Fig-3: Percentage distribution of six common skin diseases in neonates.

25 other skin diseases like, vulvovaginitis, pigmentary disorder, haemangioma, alopecia, drug reaction, oral ulcer, lichen striatum, paronychia, skin changes due to nutritional deficiencies, hyperhydrosis, ITP, TEN, SSSS and acrodermatitis were less than one percent in frequency each. 
Table IV

Scabies with secondary infection or eczematization in different age groups in children below 1 yr age (n=9293)

\begin{tabular}{lcccc} 
& $\begin{array}{c}\text { Total number } \\
\text { of patient }\end{array}$ & $\begin{array}{c}\text { Number of } \\
\text { patient with Scabies }\end{array}$ & $\begin{array}{c}\text { Secondary bacterial } \\
\text { infection (\%) }\end{array}$ & $\begin{array}{c}\text { Eczematization } \\
(\%)\end{array}$ \\
\hline Neonates & 649 & 9 & $3(33)$ & $2(22.22)$ \\
29 days to 3 month & 1534 & 349 & $280(80.23)$ & $82(23.50)$ \\
3 to 6 month & 2207 & 508 & $394(77.56)$ & $118(23.23)$ \\
6 month to 1 yr & 4903 & 1312 & $892(67.99)$ & $254(19.36)$ \\
\hline Total & 9293 & 2178 & $1569(72.03)$ & $456(20.94)$ \\
\hline
\end{tabular}

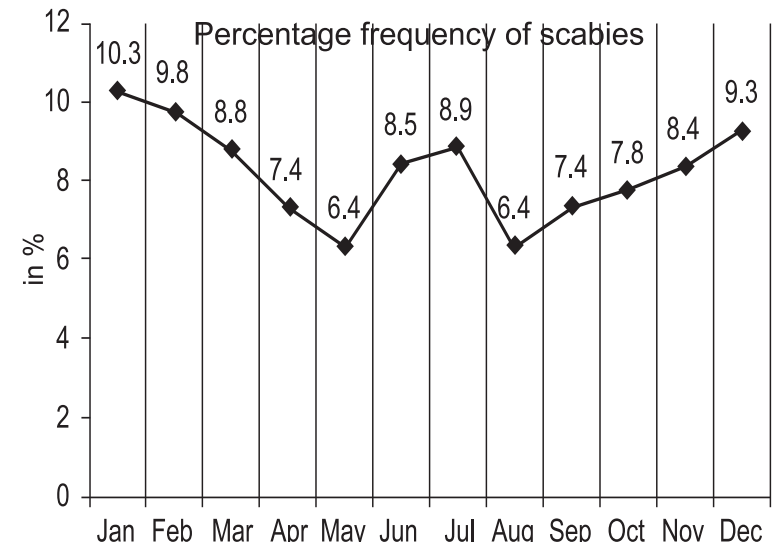

Fig.-4: Percentage frequency of scabies during different months of years 2010 and 2011 in children below 1 year of age (year 2012 excluded in the graphical presentation)

\section{Discussion}

Pediatric dermatoses up to one year age group is a large population and constituted about one fourth of pediatric skin diseases in our series. Similar patient population (28.7\%) was found in a study done in Kuwait. ${ }^{12}$ In a study in Iraq ${ }^{13} 30.7 \%$ of pediatric patients were below one year of age and the distributions were eczematous dermatitis in $34.24 \%$, atopic dermatitis in $11.24 \%$, seborrheic dermatitis in $7.49 \%$, impetigo $0.26 \%$, scabies $0.26 \%$, fungal infection $3.1 \%$

In our study, we found different types of eczema as the commonest disorder (55.41\%), followed by bacterial infections and scabies.

Seborrheic dermatitis occurs approximately in 3-5\% of the general population and affects all races. ${ }^{14}$ The condition mainly occurs at two age peaks, early on in infancy, during the first few months of life, or in adulthood between the ages of 30 and 60 . This disease appears to affect more in males than in females of both infantile and adult onset of the disease. ${ }^{15}$ In our series we found seborrheic dermatitis was common in age groups of 29 days to 3 months and also 3 to 6 months ( $48,7 \%$ and $43.3 \%$ respectively) and was less prevalent in age group 6 month to 1 year. Distribution was slightly higher in males than in females (33.2\% vs. $31.2 \%$ ) (Table III).

Pediatric dermatoses show different pattern in different countries and they vary according to socioeconomic status of the country. Though infection-related diseases are common in developing countries the change in distribution pattern of dominant pediatric dermatoses from infection \& infestation to eczema in our series can possibly be attributed to the better hygienic condition and availability of treatment facility. This pattern of skin diseases with eczema dominating over infections and infestations was also seen in Singapore and Thailand. ${ }^{16}$, ${ }^{17}$ Exposure to allergens in a metropolitan society might be responsible for higher number of eczema.

\section{Conclusion}

From our study, it can be concluded that eczema, bacterial infections, scabies and superficial fungal infections are the commonest skin diseases in infants. Erythema neonatorum, seborrheic dermatitis, candidiasis and impetigo are commonest skin diseases in newborns. Among bacterial infections impetigo is the commonest. Seborrheic dermatitis is the commonest form of eczema and is found more in first six months of life than later half of infancy. Scabies show peak distribution during winter season.

\section{References}

1. Skin. In : Junqueira LC, Carneiro J, Kelley R. Basic Histology. $8^{\text {th }}$ edition. Connecticut, USA : Appleton \& Lange; 1995: p. 346-58. 
2. Fluhr JW, Darlenski R, Taieb A, et al. Functional Skin Adaptation in Infancy-almost Complete but Not Fully Competent. Exp Dermatol 2010; 19(6): 483-92.

3. Stamatas GN, Nikolovski J, Luedtki MA, Kollias N, Wiegand BC. Infant Skin Microstructure Assessed in Vivo Differ from Adult Skin in Organization and at the Cellular Level. Pediatr Dermatol 2010; 27(2): 125-31.

4. Darmstadt GL, Dinulos JG. Neonatal Skin Care. Pediatr Clin North Am 2000; 47(4): 757- 82.

5. Matiz C, Tom WL, Eichenfield LF, et al . Children with Atopic Dermatitis Appears Less Likely To Be Infected with Community Acquired MRSA: the San Diego Experience. Pediatr Dermatol 2011; 28(1): 6-11.

6. Chiou YB, Blume-Peytavi U. Stratum Corneum maturation. A review of neonatal skin function. Skin Pharmacol Physiol 2004;17(2): 57-66.

7. Shwayder T, Akland T. Neonatal skin barrier: structure, function, and disorders. Dermatol Ther 2005; 18(2): 87103.

8. Leung DYM. Atopic Dermatitis (Atopic Eczema). In: Behrman RE, Kliegman RM, Jenson HB, editors. Nelson Textbook of Pediatrics. 17th edition. New Delhi, India: Elsevier; 2004: p. 774-75.

9. Chang MW, Orlow SJ. Neonatal, Pediatric, and Adolescent Dermatology. In: Wolff K, Goldsmith LA,Katz SI, editors.
Fitzpatrick's Dermatology. in General Medicine. Seventh Edition. New York: McGrawHill; 2008: p. 935-36.

10. Javed M, Jairamani C. Pediatric dermatology: an audit at Hamdard University Hospital, Karachi. J Pakistan Assoc Dermatologists 2006; 16: 93-96.

11. Javed M. Neonatal dermatology at tertiary care teaching hospital. Eastern J Med 2010; 15: 90-92

12. Nanda A, Al-Hasawi F, Alsaleh QA. A prospective survey of pediatric dermatology clinic patients in Kuwait: an analysis of 10,000 cases. Pediatr Dermatol 1999; 16(1): 6-11.

13. Kathem K Al-Rubiay. Pediatric Dermatology: A Study of Pattern of Skin Diseases Among Children Attending Basrah Maternity and Children Hospital. Med J Basrah University 2005; 23(1): 27-30.

14. Burton JL, Pye RJ. Seborrhea is not a feature of seborrheic dermatitis. Br Med J 1983; 286(6372):1169-70.

15. Schwatz RA. Janusz CA, Janniger CK. Seborrheic Dermatitis: An Overview. Am Fam Physician 2006; 74: 125-32.

16. Giam YC. Skin diseases in children in Singapore. Ann Acad Med Singapore 1988; 17(4): 569-72.

17. Wisuthsarewong W, Viravan S. Analysis of skin diseases in a referral pediatric dermatology clinic in Thailand. $\mathrm{J}$ Med Assoc Thai 2000; 83(9): 999-1004. 